\title{
How the Bcl-2 family of proteins interact to regulate apoptosis
}

\author{
Mark F van Delft ${ }^{1,2}$, David CS Huang ${ }^{1}$ \\ ${ }^{I}$ The Walter and Eliza Hall Institute of Medical Research, 1 G Royal Parade, Parkville, Victoria 3050, Australia; ${ }^{2}$ Department of \\ Medical Biology, University of Melbourne, Parkville, Victoria 3010, Australia
}

Commitment of cells to apoptosis is governed largely by protein-protein interactions between members of the Bcl-2 protein family. Its three sub-families have distinct roles: the BH3-only proteins trigger apoptosis by binding via their BH3 domain to pro-survival relatives, while the pro-apoptotic Bax and Bak have an essential downstream role involving disruption of organellar membranes and induction of caspase activation. The BH3-only proteins act as damage sensors, held inert until their activation by stress signals. Once activated, they were thought to bind promiscuously to pro-survival protein targets but unexpected selectivity has recently emerged from analysis of their interactions. Some BH3-only proteins also bind to Bax and Bak. Whether Bax and Bak are activated directly by these BH3-only proteins, or indirectly as a consequence of BH3-only proteins neutralizing their pro-survival targets is the subject of intense debate. Regardless of this, a detailed understanding of the interactions between family members, which are often selective, has notable implications for designing anti-cancer drugs to target the Bcl-2 family.

Cell Research (2006) 16:203-213. doi:10.1038/sj.cr.7310028; published online 13 February 2006

Keywords: apoptosis, cell death, Bcl-2, Mcl-1, BH3, BH3 mimetic

\section{Introduction}

The essential components to the apoptotic pathway are conserved in most metazoans $[1,2]$. Many of the proteins that conduct this cell death process are constitutively expressed in viable cells, but under favorable growth conditions, their pro-apoptotic activities are held in check by Bcl-2 and its pro-survival relatives [3, 4]. A complex network of interactions among proteins of the Bcl-2 family integrates signals of cellular stress and well-being, forming a central checkpoint that determines whether a cell will live or die.

\section{The Bcl-2 Family}

Members of the Bcl-2 family are related to one another due to their conserved regions termed $\underline{B} \mathrm{cl}-2$ homology $(\mathrm{BH})$ domains $[5,6]$, and can function either as pro-survival or pro-apoptotic molecules (Figure 1). The mammalian members with pro-survival activity share up to four regions

Correspondence: David CS Huang

E-mail: huang_d@wehi.edu.au of sequence homology (BH1-4), and include Bcl-2, Bcl- $\mathrm{x}_{\mathrm{L}}$, Bcl-w, Mcl-1 and A1. The pro-apoptotic members of the family can be subdivided into two functionally and structurally distinct classes. The BH3-only proteins (Bim, Puma, Bid, Bad, Bik, Bmf, Hrk, Noxa) share only the $\mathrm{BH} 3$ region of homology and serve as upstream sentinels, becoming activated in response to various forms of cellular stress [7], whereas Bax and Bak contain multiple $\mathrm{BH}$ domains (BH1, $\mathrm{BH} 2$ and $\mathrm{BH} 3$ ) and are required downstream of $\mathrm{BH} 3$-only proteins to induce apoptosis [8-11].

\section{Pro-survival proteins}

The pro-survival activity of Bcl-2 and its closest relatives has been clearly demonstrated in both overexpression and gene targeting studies. Overexpression of any of the five pro-survival members protects cells against apoptosis induced by a variety of cytotoxic stimuli [3], suggesting functionally overlapping roles for these proteins. Gene targeting studies, however, reveal a more refined division of labor among these proteins in vivo, perhaps related to their relative expression in diverse cell types and tissues $[3,12]$. Bcl-2, for example, is required for the survival of mature lymphocytes, melanocyte stem cells and cells of the developing kidney [13-15], Bcl-w for Sertoli cells in 


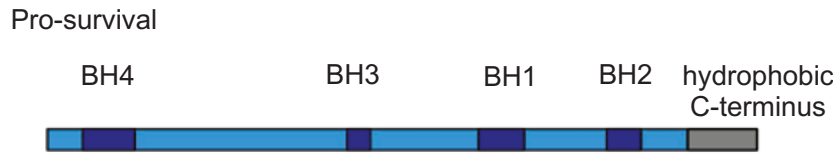

Pro-apoptotic

Bax/Bak

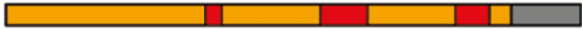

BH3-only

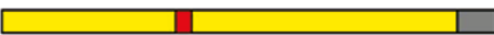

Bcl-2, Bcl- $\mathrm{x}_{\mathrm{L}}, \mathrm{Bcl}-\mathrm{w}$,

Mcl-1, A1

Bax, Bak

Bad, Bid, Bim, Bik, Blk, Hrk, Noxa, Puma

Figure 1 Sequence homology between proteins of the Bcl-2 family. The Bcl-2 family can be divided into those that promote survival and those that promote apoptosis. Boxes indicate the conserved $\underline{B} \mathrm{cl}-2$ homology $(\mathrm{BH})$ domains. Most members also share the hydrophobic C-terminal tail, although some (Bad, Bid, Noxa, Puma, Bmf) do not bear such an obvious sequence.

the testis [16, 17], and A1 for neutrophils [18]. Embryos lacking either $m c l-1$ or $b c l$ - $\mathrm{x}_{\mathrm{L}}$ do not survive development; those lacking Mcl-1 fail to implant [19] while those lacking Bcl- $\mathrm{x}_{\mathrm{L}}$ die in utero with extensive apoptosis throughout their developing nervous and hematopoietic systems [20]. Chimeras and conditional knockout mice have demonstrated that Mcl-1 is necessary for the survival of hematopoietic progenitors, and mature B- and T- lymphocytes [21, 22], whereas that $\mathrm{Bcl}-\mathrm{x}_{\mathrm{L}}$ is required for the survival of mature erythrocytes $[23,24]$.

A precise molecular mechanism by which pro-survival proteins keep cells alive is not yet established, but structural studies on these molecules are making progress in this area [25]. The 3-dimensional structures of Bcl-2 [26], Bcl- $\mathrm{x}_{\mathrm{L}}$ [27, 28], Bcl-w [29, 30], and Mcl-1 [31] have all been solved. Each has a similar overall helical fold centered on a core hydrophobic helix with the BH1-3 domains arranged to expose a hydrophobic groove on the molecule. The integrity of this hydrophobic groove is required both for pro-survival activity [5] and for the binding of pro-survival proteins to their cognate pro-apoptotic partners [28, 32, 33].

\section{BH3-only proteins}

The BH3-only subset of pro-apoptotic proteins can bind with high affinity to certain pro-survival molecules and trigger apoptosis when overexpressed [34]. The BH3 domain itself is necessary for both of these activities [6]. It adopts an amphipathic a-helical conformation that inserts into the hydrophobic groove of a pro-survival protein $[28,32,33]$, thereby neutralizing the activity of its target to promote apoptosis. $\mathrm{BH} 3$ domains possess four conserved hydrophobic residues spaced at intervals of three to four residues apart, so as to lie along one face of the amphipathic $\alpha$-helix. Each of the four conserved hydrophobic residues inserts into a distinct pocket in the hydrophobic groove of the target pro-survival protein. Mutation of these residues reduces the affinity of $\mathrm{BH} 3$ proteins for their targets thereby compromising their proapoptotic activity $[32,33]$.

Particular apoptotic stimuli elicit the response of particular BH3-only proteins and these have been elucidated through genetic studies. Bim is a critical sentinel that prevents autoimmunity, as it is required for deleting autoreactive $\mathrm{B}$ - and T- cells $[35,36]$ and for the termination of acute T-cell responses [37, 38]. Mice deficient in Bim accumulate excess lymphocytes, macrophages, and granulocytes in their immune systems and in vitro these cells are more resistant to apoptosis induced by cytokine withdrawal and perturbation in calcium homeostasis [39]. In contrast, both Puma [40, 41] and Noxa [42] are transcriptionally up-regulated by p53 in response to DNA damage, and while Puma is important for $\mathrm{p} 53$-dependent apoptosis in a range of cell types, Noxa's role in this pathway appears to be restricted to fibroblasts and intestinal epithelial cells $[43,45]$. Loss of Puma also protects lymphocytes from apoptosis induced by cytokine withdrawal or treatment with gluccocorticoids, phorbol ester, or staurosporine [43, 44]. Bad contributes to apoptosis in mammary epithelial cells deprived of epidermal growth factor (EGF) [46], while Bid participates in the apoptosis of fibroblasts and hepatocytes induced by death receptors [47], and Bmf may be important for detachment-induced apoptosis (anoikis) in certain cell types [48].

\section{Bax and Bak}

Despite having 3-dimensional structures that are very similar to the Bcl-2 pro-survival proteins [49], Bax and Bak paradoxically promote rather than oppose apoptosis. While mice deficient in either Bax or Bak alone have only mild abnormalities, presumably due to functional redundancy 
between them, their combined loss has a dramatic effect on apoptosis signaling $[10,11]$. Most Bax/Bak-deficient mice die perinatally and the few that do survive to adulthood have an accumulation of superfluous cells in various tissues. Different cell types derived from these mice do not undergo apoptosis when treated with a range of cytotoxic stimuli and cannot be killed by overexpressing BH3-only proteins $[8,9,50]$. Bax and Bak must therefore lie downstream of BH3-only proteins in the apoptotic pathway. Furthermore, hematopoietic cells lacking both Bax and Bak not only fail to undergo apoptosis when deprived of their requisite growth factors, but they also retain their capacity to proliferate again when appropriate cytokine stimulation is restored - even after several weeks of starvation [51] illustrating that $\mathrm{Bax} / \mathrm{Bak}$ activation forms a critical point of commitment to apoptosis.

\section{Features of Bax and Bak activation}

Bax mainly resides in the cytosol of healthy cells as a soluble monomeric protein [52-54]. This is despite the fact that it shares a C-terminal hydrophobic tail anchor sequence that drives many other Bcl-2 family proteins to be constitutively associated with the membranes of intracellular organelles [55-58]. In the structure of soluble monomeric Bax, which reflects its inactive conformation, this tail anchor domain folds back into a hydrophobic pocket that corresponds to the groove on pro-survival molecules targeted by BH3-only proteins [49]. In response to apoptotic cues, Bax undergoes conformational changes at both its $\mathrm{N}$ - and $\mathrm{C}$ - termini, translocates to the mitochondrial outer membrane, and forms large oligomeric complexes [53, 59-61].

Bak, on the other hand, is constitutively integrated in the mitochondrial outer membrane, but in response to apoptotic stimuli also changes conformation and forms oligomeric complexes [53, 61-63]. Cross-linking studies suggest that the Bax and Bak complexes are homo-oligomeric and that they interact with one another in dying cells [64]. Reports have varied regarding the involvement of other proteins, including VDAC [65, 66], tBid [67] and Map-1 [68], in these oligomeric complexes.

Oligomerized Bax and Bak facilitate the release of cytochrome $c$ from the mitochondrial intermembrane space to the cytosol, where it binds to Apaf-1 and coordinates the formation of the Apaf-1/Caspase-9 apoptosome [1, 69]. How Bax and Bak alter the permeability of the mitochondrial outer membrane is still poorly understood. One hypothesis is that activated Bax and Bak either directly or indirectly influence the properties of an existing mitochondrial pore - thought to be composed of the voltage dependent anion channel (VDAC), the adenine nucleotide translocator (ANT) and cyclophilin D (CypD) - to affect a permeability transition that results in swelling of the mitochondrial matrix and leads to rupture of the outer membrane [70]. It has been observed however, that cytochrome $c$ can be completely released during apoptosis without the loss of outer membrane integrity [71]. Furthermore, mice lacking cyclophilin D develop normally despite having mitochondria that do not properly undergo permeability transition during apoptosis [72-74]. Their cells release cytochrome $c$ and undergo programmed cell death in response to apoptotic stimuli as efficiently as wild-type cells but are somewhat resistant to death induced by necrotic stimuli. Thus, a critical role for the mitochondrial permeability transition in apoptosis seems unlikely.

Based on structural similarity to bacterial pore-forming toxins, an alternative hypothesis is that the aggregates of Bax and Bak may themselves breach the integrity of the mitochondrial outer membrane and allow cytochrome $c$ to be released to the cytosol. Indeed recombinant Bax is capable of oligomerizing and forming pores in artificial liposomes that are large enough to release molecules such as cytochrome $c$ [75-77]. Following the induction of apoptosis and translocation of Bax to mitochondria, the electrophysiological properties of the predominant outer membrane channels VDAC and TOM (translocase outer membrane) remain unchanged, but a channel with novel properties can be detected [78]. This channel, termed the mitochondrial apoptosis-induced channel (MAC) contains Bax protein and its properties are indistinguishable from oligomerized Bax in protein-free synthetic membranes [79]. These observations are consistent with a simple model wherein Bax and Bak homo-oligomerize during apoptosis to form pores in the mitochondrial outer membrane through which cytochrome $c$ can escape into the cytosol. A related unresolved issue is the role of Bax and Bak located on other intracellular membranes, such as that of the outer membrane of the endoplasmic reticulum [80].

\section{Regulation of Bax and Bak by other Bcl-2 family proteins}

\section{Role of BH3-only proteins in Bax/Bak activation}

The regulatory mechanism of the activation of Bax and Bak by the other subsets of the Bcl-2 family remains controversial (Figure 2). It is clear that overexpressing Bcl-2 blocks the changes associated with Bax and Bak in apoptotic cells $[53,60]$, and that $\mathrm{BH} 3$-only proteins require Bax or Bak to induce apoptosis $[8,9]$, but these observations are compatible with several models. Challenging the original notion that once activated, all $\mathrm{BH} 3$-only proteins trigger apoptosis through a common mode of action, several recent reports have demonstrated that different classes BH3-only proteins can be distinguished [81-83]. However, the models 
A Directly activating Bax/Bak

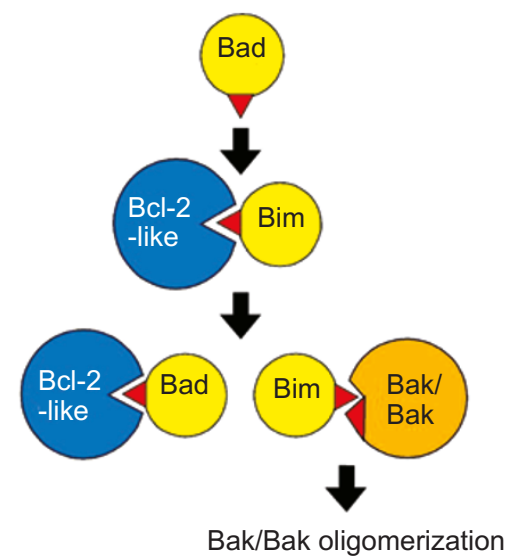

B Neutralizing pro-survival proteins

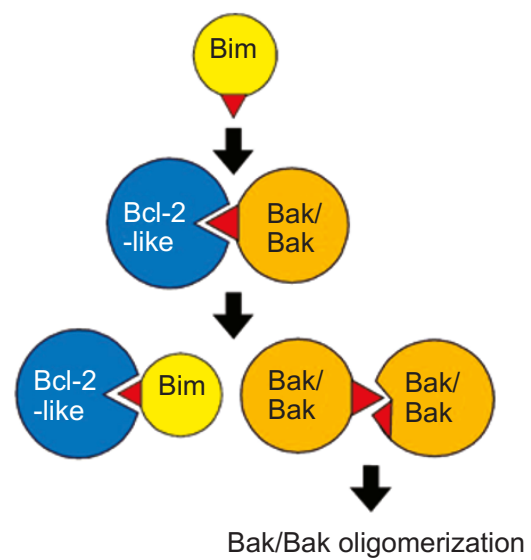

Figure 2 Models for Bax/Bak activation by BH3-only proteins. (A) Direct Activation Model. BH3-only proteins can be divided into two groups: "sensitizers" or "derepressors" (e.g. Bad) that bind only to pro-survival proteins and "activators" (e.g. Bim) that can also directly engage Bax and Bak. "Sensitizers/derepressors" induce apoptosis by displacing "activators" from pro-survival proteins, which then proceed to trigger Bax/Bak activation [82, 83]. (B) Pro-survival Neutralization Model. Pro-survival proteins inhibit Bax and Bak, perhaps through direct interaction as has been demonstrated for Bak [93]. BH3-only proteins induce apoptosis by neutralizing pro-survival molecules and Bax/Bak activation occurs spontaneously in the absence of pro-survival activity [81]

put forth for precisely how the $\mathrm{BH}$-only proteins regulate Bax and Bak activation in these studies differ markedly.

Several studies have favored a model in which all BH3only proteins have the capacity to bind Bcl-2 pro-survival proteins and a select few (Bim, tBid, and possibly Puma) also have the capacity to directly bind and activate Bax and Bak [82-84]. In this model (Figure 2A), Bax and Bak cannot be activated in the absence of a "direct activator" of the Bim/tBid/Puma class. The BH3-only proteins that lack the capacity to directly activate Bax and Bak (Bad, Bik, Hrk, Noxa), termed "sensitizers" or "derepressors", induce apoptosis by binding to pro-survival proteins and displacing direct activators, thereby activating Bax and Bak indirectly. Consistent with this model (Figure 2A), the affinity of a BadBH3 peptide for Bcl-2 is greater than that of a BidBH3 peptide and the former efficiently displaces bound BidBH3 peptide from Bcl-2, but not vice versa [83]. These studies were performed either in intact cells or with mitochondrial preparations that contained other members of the Bcl-2 protein family, so precluding a definitive conclusion that $\mathrm{Bim} / \mathrm{tBid} / \mathrm{Puma}$ act to directly activate Bax or Bak. However, the more recent work by Kuwana and colleagues contends that Bim or Bid BH3 peptides can cooperate with Bax to permeabilize protein-free synthetic liposomes, arguing that this effect is direct $[77,82]$.

Neither of these studies provides evidence for a direct interaction between either $\mathrm{tBid}$ or Bim with Bax or Bak, and prior studies $[63,84-86]$ have only reported such in- teractions with Bax in the presence of non-ionic detergents that open up its structure [52]. Only the poorly expressed shorter isoforms of Bim but not the more abundant longer isoforms interact with Bax [85]. Surprisingly, tBid and Puma appear to interact with the first a-helix of Bax rather than with the hydrophobic groove formed by the BH1-3 domains [84]. Furthermore, Bim, tBid, and Puma have not been detected in the oligomeric complexes of Bax or Bak in apoptotic cells [53, 61], and physiological binding between endogenous BH3-only proteins and Bax or Bak has not been detected in either healthy cells or cells treated with an apoptotic stimulus [87]. In this regard, the hypothesis that Bim and tBid may simultaneously act with Bax/Bak and lipids in the mitochondrial outer membrane to achieve permeabilization in the absence of a direct interaction between these components has been proposed [77, 88], though how this might be achieved is unclear.

While the interaction of $\mathrm{BH} 3$-only proteins with $\mathrm{Bax}$ and Bak continues to be a contentious issue, it is clear that all $\mathrm{BH} 3$-only proteins bind with high affinity to at least some members of the Bcl-2 pro-survival family. A comprehensive survey of the interactions between $\mathrm{BH} 3$-only proteins and Bcl-2 pro-survival proteins [81] raises an alternative model (Figure 2B) that explains why certain $\mathrm{BH} 3$-only proteins (Bim, Puma) are more potent inducers of apoptosis than others (Bad, Noxa). By measuring the affinity of peptides corresponding to the $\mathrm{BH} 3$ domains of the established mammalian BH3-only proteins (Bim, Puma, Bid, Bad, Bik, Bmf, 
Hrk, Noxa) for their Bcl-2 pro-survival partners (Bcl-2, Bcl- $\left.\mathrm{x}_{\mathrm{L}}, \mathrm{Bcl}-\mathrm{w}, \mathrm{Mcl}-1, \mathrm{~A} 1\right)$, it was discovered that some of the $\mathrm{BH} 3$-only proteins (Bim, Puma) bind with high affinity to all pro-survival members, while the others have more restricted binding profiles. Those that bind promiscuously are also potent inducers of apoptosis in killing assays, and those that bind selectively to only certain pro-survival proteins are less potent, to the extent that stable overexpression of these $\mathrm{BH} 3$-only proteins is compatible with clonogenic growth. These results suggest that the Bcl-2 pro-survival proteins may have unique roles in maintaining cell viability, and that each of the different classes of pro-survival must be neutralized to induce apoptosis. Interestingly, when BH3only proteins with complementary binding profiles, such as Noxa which neutralizes Mcl-1 and A1, and Bad which neutralizes Bcl-2, Bcl- $\mathrm{x}_{\mathrm{L}}$, and Bcl-w, are co-expressed in cells, apoptosis is induced as efficiently as when the panspecific BH3-only protein Bim is expressed [81]. This seems to be at odds with the claims that a direct activator of Bax or Bak is required to trigger apoptosis, because in this model (Figure 2A) both Bad and Noxa are "sensitizers/derepressors". It cannot be ruled out, however, that the co-expressed Bad and Noxa liberate sufficient levels of endogenous Bim, tBid, or Puma to activate Bax and induce apoptosis in these otherwise unstimulated cells. A definitive resolution of this issue awaits the analysis of mice lacking combinations of the $\mathrm{BH} 3$-only proteins proposed to directly activate Bax and Bak.

\section{Role of pro-survival proteins in controlling Bax/Bak}

Do the Bcl-2 pro-survival proteins play a passive role in regulating the activation of Bax and Bak simply by functioning as sinks for "direct activators" such as Bim, and thereby establishing a threshold of $\mathrm{BH} 3$-only protein induction required to trigger apoptosis? Or do they play a more proactive role? That $\mathrm{Bcl}-\mathrm{x}_{\mathrm{L}}$ and $\mathrm{Bcl}-\mathrm{w}$ continue to bind $\mathrm{BH} 3$-only proteins with high affinity but cease to be biologically active inhibitors of apoptosis when their membrane targeting $\mathrm{C}$-terminal residues are deleted would argue against this simple model $[29,89]$. How then do the Bcl-2 family pro-survival proteins inhibit Bax/Bak activation? One possibility is that they might render proteins or lipid environments on the mitochondrial membrane that are required for Bax/Bak activation inaccessible. Alternatively, pro-survival molecules might sequester Bax and Bak, restraining them through a direct interaction. In fact Bax was first identified as a Bcl-2 binding protein [90], but it is unlikely that they interact significantly in healthy cells because Bcl-2 is membrane associated [91], whereas Bax is predominantly soluble and monomeric [52, 54]. It is possible however that $\mathrm{Bcl}-2$ might bind to $\mathrm{Bax}$ at the mitochondria following an apoptotic stimulus to prevent its further activation and oligomerization into cytochrome $c$ conducting pores. In this regard it is worth noting that the interaction between Bcl-2 and Bax is dependent upon the use of non-ionic detergents that cause Bax to undergo a conformational change and expose an $\mathrm{N}$-terminal epitope, similar to that observed in cells after apoptotic stimulation [52]. However, whether the overall conformation of Bax induced by non-ionic detergents and apoptotic signaling is the same is not clear. Thus, even though several prosurvival proteins have been reported to bind Bax via its $\mathrm{BH} 3$ domain in the presence of non-ionic detergents [92], whether any of these interactions reflect a physiological role in directly regulating Bax remains uncertain.

Unlike Bax, Bak is normally associated with membranes in healthy cells, including the mitochondrial outer membrane, and there is clear evidence that it is regulated through direct interactions with $\mathrm{Bcl}-2$ pro-survival proteins. In healthy mammalian cells, binding studies have demonstrated that Bak is engaged in complexes with both Mcl-1 and Bcl- $\mathrm{x}_{\mathrm{L}}$ but not other pro-survival proteins such as $\mathrm{Bcl}-2$ [93]. Accordingly, both $\mathrm{Mcl}-1$ and $\mathrm{Bcl}-\mathrm{x}_{\mathrm{L}}$ were identified biochemically as the critical inhibitors of mitochondrial damage following apoptotic stimuli that cause Bak activation. It is also now established that Mcl-1 and $\mathrm{Bcl}-\mathrm{x}_{\mathrm{L}}$ sequester Bak in healthy cells through a direct interaction with its $\mathrm{BH} 3$ domain, and that when both Mcl-1 and $\mathrm{Bcl}-\mathrm{x}_{\mathrm{L}}$ are neutralized by $\mathrm{BH} 3$-only proteins to displace the Bak BH3 domain, Bak-dependent apoptosis ensues [93]. Particularly convincing is the fact that while expression of Noxa does not kill wild-type cells, presumably because this $\mathrm{BH} 3$-only protein neutralizes Mcl-1 but not $\mathrm{Bcl}-\mathrm{x}_{\mathrm{L}}$, it efficiently induces apoptosis in cells lacking $\mathrm{Bcl}-\mathrm{x}_{\mathrm{L}}$. Again, this data argues against models that purport the requirement of a direct activator of Bax or Bak to initiate apoptosis (Figure 2A). In this experimental system it seems unlikely that sufficient levels of direct activators would be mobilized after Noxa expression as Bcl-2 and Bcl-w (in the constitutive absence of $\mathrm{Bcl}-\mathrm{x}_{\mathrm{L}}$ ) are spared by this $\mathrm{BH}$-only protein, they would be available to capture any Bim, tBid, or Puma released from Mcl-1.

The mitochondrial outer membrane protein VDAC2 has also been reported to restrain the activity of Bak [66], but cells lacking VDAC2 remain viable while those in which both Bcl- $\mathrm{x}_{\mathrm{L}}$ and Mcl-1 are neutralized die. Therefore it would seem that Bcl- $\mathrm{x}_{\mathrm{L}}$ and Mcl-1 have greater influence in preventing Bak activation than does VDAC2.

\section{Mcl-1: a linchpin in the network of anti-apoptotic regulators}

Mcl-1 plays a critical role in preventing inappropriate activation of Bax and Bak [93, 94], the key downstream 
mediators of cell death. Its exceptional importance within the pro-survival sub-family is underscored by the severe consequences of disrupting its expression, either prior to development [19] or in adult tissues [21, 22]. Considering Mcl-1's joint role with Bcl- $\mathrm{x}_{\mathrm{L}}$ as one of the two regulators of Bak [93], this might result from Mcl-1 being the only restraint on Bak activation in cells that express insufficient levels of $\mathrm{Bcl}-\mathrm{x}_{\mathrm{L}}$. It could also suggest that Mcl-1 might have additional pro-survival functions that have yet to be elucidated.

Mcl-1 has been reported to act at an apical step of the apoptotic pathway [95] and must be eliminated or neutralized for apoptosis to proceed. It is degraded by the proteasome following treatment with genotoxic agents such as UV-irradiation. If its degradation is blocked with proteasome inhibitors, these stimuli do not induce rapid cell death [95]. Moreover, apoptosis cannot be induced by overexpressing BH3-only proteins unless Mcl-1 is neutralized [81]. Overexpressing Noxa causes Mcl-1 to be degraded in a proteasome-dependent manner [93], but not all $\mathrm{BH} 3$ proteins that bind to Mcl-1 have this effect. For example, Puma instead stabilizes Mcl-1 [96], but still induces apoptosis when overexpressed [81]. It would seem, therefore, that neutralizing Mcl-1's pro-survival activity is sufficient for apoptosis to proceed and that its degradation is not strictly required. It is possible that the degradation of Mcl-1 after DNA damage helps to ensure irreversible commitment to apoptosis after such cellular insults.

The potent influence of Mcl-1 on cellular viability necessitates that its activity be tightly regulated. This is achieved through multiple overlapping levels of transcriptional and post-translational control. Mcl-1 is a labile protein with a short half-life [57], owing to its constitutive ubiquitination by the E3-ligase Mule [97] and concomitant degradation by the proteasome. For this reason, Mcl-1 expression drops rapidly after DNA damage [95] or other insults that similarly trigger a global arrest of protein translation [98]. In many cell types, Mcl-1 expression is maintained or induced by cytokine signaling. Several cytokines that promote cell survival, including IL-3, IL-5, IL-6, IL-7, IL-11, IL-15, SCF, and VEGF, stimulate Mcl-1 transcription and many of these also require Mcl-1 for their pro-survival activity $[21,22,99-101]$. Some of these cytokines might further enhance Mcl-1 expression by activating intracellular kinase cascades that phosphorylate and stabilize the protein [102]. In contrast, the stress induced kinase JNK phosphorylates Mcl-1 and this diminishes its anti-apoptotic activity without altering the stability of the protein [103]. These regulatory mechanisms determine the extent to which $\mathrm{BH} 3$-only proteins are required to neutralize Mcl-1 during apoptosis signaling, and offer potential opportunities to alter the prosurvival activity of Mcl-1 pharmacologically.

\section{Manipulating the Bcl-2 family for therapeutic ben- efit}

Many conventional cytotoxic therapies, such as DNA damaging agents, induce apoptosis indirectly by causing cellular stress and activating BH3-only proteins. Such treatments often fail when tumors overexpress pro-survival proteins, or when they acquire mutations in the signaling pathways leading from cytotoxic stress to $\mathrm{BH} 3$-only protein activation [104]. Mutations that inactivate the $\mathrm{p} 53$ pathway, severing the link between DNA damage and BH3only protein induction are particularly common in tumors [105]. To circumvent this, anti-cancer therapies that directly engage the core apoptotic machinery are attractive, and both peptide and small-molecule based drugs that mimic that activity of $\mathrm{BH} 3$-only proteins are being developed to bypass these common complications that hinder the action of conventional cytotoxic agents.

Peptides corresponding to intact $\mathrm{BH} 3$ domains are appealing candidates, but their potential use as drugs is constrained by the limited ability of such peptides to cross membranes and their stability in vivo. Several attempts have been made to increase their membrane permeability by attaching carrier sequences such as the antennapedia penetration sequence [106, 107], decanoic acid [108], or poly-D-arginine [83], but these molecules often cause nonspecific toxicity related to their biophysical properties. The most successful approach to date has been to chemically constrain $\mathrm{BH} 3$ peptides into an a-helical conformation with a hydrocarbon linker [109]. Remarkably, the constrained peptides are cell permeable and have been demonstrated to induce apoptosis in leukemia cells in vitro and inhibit their growth in mouse xenograft models.

Small molecules that target the hydrophobic groove of pro-survival proteins and mimic the action of BH3-only proteins have also been sought using both in silico screens (e.g. [110]) and physical screens of compound libraries (e.g. [111]). The potential BH3 mimetics identified in these studies, however, bind to pro-survival molecules with much lower affinity (mM range) than do BH3-only proteins (nM range) $[33,81]$, and the mechanism with which they kill cells is not firmly established $[112,113]$. These compounds may prove to be useful leads for the development of high affinity BH3 mimetics if they can be improved with traditional medicinal chemistry or through structure-based approaches similar to the one used recently by Abbott Laboratories [114]. Oltersdorf and colleagues identified two small molecules in an NMR-based screen that bound weakly (Kds in the hundreds of $\mathrm{mM}$ range) to adjacent pockets in the hydrophobic groove of $\mathrm{Bcl}-\mathrm{x}_{\mathrm{L}}$. These two lead molecules were connected with a linker that allowed both groups to simultaneously interact with their respec- 
tive pockets and the resulting derivative bound $\mathrm{Bcl}-\mathrm{x}_{\mathrm{L}}$ with much higher affinity $(\mathrm{Ki}=36 \mathrm{nM})$. Further structure-based improvements yielded the compound ABT-737, which bound with low nanomolar affinity to $\mathrm{Bcl}-\mathrm{x}_{\mathrm{L}}, \mathrm{Bcl}-2$ and Bcl-w, but not to Mcl-1 or A1. ABT-737 effectively induced apoptosis as a single-agent in cultured lymphoma and small cell lung carcinoma (SCLC) cell lines as well as primary patient samples, and caused regression of established SCLC tumors in mouse xenograft models.

Because ABT-737 does not neutralize Mcl-1 or A1, it is anticipated that this drug will be most effective as a single agent against tumors that express low levels of these prosurvival proteins. In tumors that resist killing by ABT-737 on its own because they express high levels of Mcl-1 or A1, combining ABT-737 with therapies that neutralize these pro-survival proteins might be beneficial. Indeed ABT-737 induced apoptosis in a variety of tumor cell lines more efficiently when it was combined with chemotherapeutics that induce DNA damage and subsequently reduce Mcl-1 expression [114].

Mcl-1 is an attractive target for therapeutic attack because it is widely expressed in tumors and because neutralizing it together with $\mathrm{Bcl}-\mathrm{x}_{\mathrm{L}}$ is sufficient to trigger Bak-dependent apoptosis (Figure 3). Because Noxa binds selectively to Mcl-1 and A1, it might be possible to generate small molecule $\mathrm{BH} 3$ mimetics with similar selectivity using the structure of a Noxa:Mcl-1 complex to drive rational drug development. Therapies that exploit

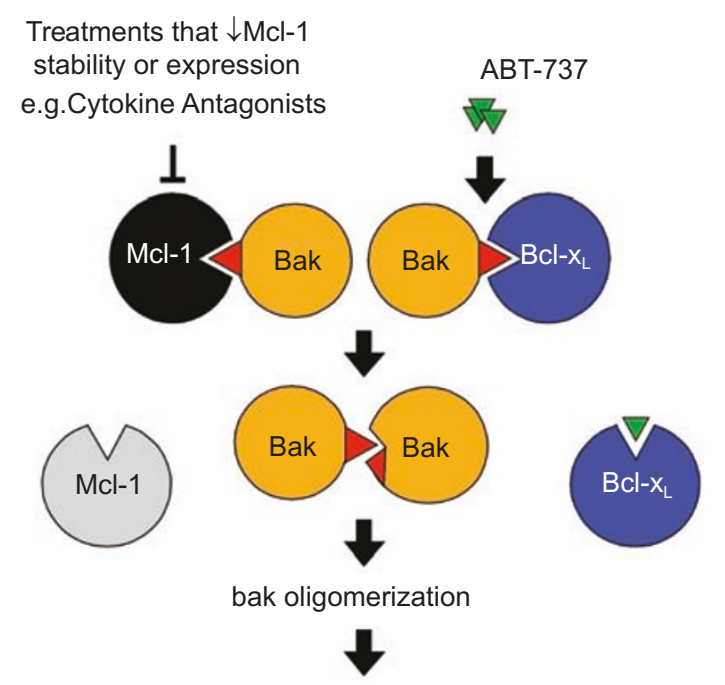

Figure 3 Inducing Bak-mediated apoptosis by targeting Mcl-1 and Bcl- $\mathrm{x}_{\mathrm{L}}$. Because Mcl-1 and Bcl- $\mathrm{x}_{\mathrm{L}}$ are the only regulators of Bak [93], promoting Mcl-1 elimination with targeted therapies and neutralizing $\mathrm{Bcl}-\mathrm{x}_{\mathrm{L}}$ with the $\mathrm{BH} 3$ mimetic $\mathrm{ABT}-737$ should be sufficient to induce apoptosis. the instability and rapid turnover of Mcl-1 are another possibility. The cyclin-dependent kinase inhibitor Seliciclib (CYC202, R-Roscovitine) is one such candidate. It causes the carboxy-terminal domain of RNA polymerase II to be dephosphorylated, thereby blocking transcription non-specifically, and has been proposed to induce apoptosis partly through the subsequent downregulation of Mcl-1 [115, 116]. Alternatively, cytokine antagonists or inhibitors of their downstream intracellular signal transduction cascades might be an effective means of sensitizing tumors in which Mcl-1 expression is dependent upon sustained growth factor signaling. Directed strategies like this might exploit a therapeutic window such that tumor cells are sensitized to killing while normal cells are spared.

\section{Conclusions}

As we continue to learn more about how Bcl-2-family proteins interact to regulate apoptosis, it is becoming clear that there is greater complexity than was first anticipated. Within the pro-survival and pro-apoptotic factions, each member has a subtly different function to the next. The selectivity with which $\mathrm{BH} 3$-only proteins neutralize prosurvival molecules and the differential regulation of Bax and Bak by certain members of the pro-survival family are among these subtleties. Further complexity will surely be uncovered in the future. It remains to be determined whether Bax, like Bak, is regulated through direct interactions with pro-survival proteins, and if so, which of these are critical. The question of whether $\mathrm{BH} 3$-only proteins directly engage Bax and Bak at the mitochondria to induce apoptosis is also unresolved. Likewise, the molecular nature of the cytochrome $c$ conducting channels remains a mystery, as does a detailed understanding of the biochemistry regulating their formation. Along with the gains made recently and discussed in this review, answers to these outstanding questions will certainly help to develop improved strategies for treating cancer by manipulating the $\mathrm{Bcl}-2$ protein family with novel therapeutics.

\section{Acknowledgements}

We thank our colleagues for many stimulating discussions and sharing ideas: J M Adams, P Bouillet, L Chen, P M Colman, S Cory, C L Day, G Dewson, W D Fairlie, J I Fletcher, R M Kluck, E F Lee, K D Mason, H Puthalakath, A W Roberts, A Strasser, D L Vaux, A H Wei and S N Willis. We apologize to many scientists and colleagues that we are unable to cite their work directly because of space limitations. Grants from the Australian NHMRC (Program Grant 257502), US NCI (CA80188 and CA43540), Leukemia and Lymphoma Society (Specialized Center of Research 7015-02), a Melbourne International Research Scholarship 
(to MFvD) and a fellowship from the NHMRC (to DCSH) support our work.

\section{References}

1 Adams JM. Ways of dying: multiple pathways to apoptosis. Genes Dev 2003; 17:2481-95.

2 Danial NN, Korsmeyer SJ. Cell death: critical control points. Cell 2004; 116:205-19.

3 Cory S, Huang DCS, Adams JM. The Bcl-2 family: roles in cell survival and oncogenesis. Oncogene 2003; 22:8590-8607.

4 Borner $\mathrm{C}$. The Bcl-2 protein family: sensors and checkpoints for life-or-death decisions. Mol Immunol 2003; 39:615-647.

5 Yin XM, Oltvai ZN, Korsmeyer SJ. BH1 and BH2 domains of Bcl-2 are required for inhibition of apoptosis and heterodimerization with Bax. Nature 1994; 369:321-3.

6 Chittenden T, Flemington $\mathrm{C}$, Houghton $\mathrm{AB}$, et al. A conserved domain in Bak, distinct from $\mathrm{BH} 1$ and $\mathrm{BH} 2$, mediates cell death and protein binding functions. EMBO J 1995; 14:5589-96.

7 Puthalakath H, Strasser A. Keeping killers on a tight leash: transcriptional and post-translational control of the pro-apoptotic activity of BH3-only proteins. Cell Death Differ 2002; 9:50512.

8 Cheng $\mathrm{EH}$, Wei $\mathrm{MC}$, Weiler $\mathrm{S}$, et al. Bcl-2, Bcl- $\mathrm{x}_{\mathrm{L}}$ sequester $\mathrm{BH} 3$ domain-only molecules preventing Bax- and Bak-mediated mitochondrial apoptosis. Mol Cell 2001; 8:705-11.

9 Zong WX, Lindsten T, Ross AJ, et al. BH3-only proteins that bind pro-survival Bcl-2 family members fail to induce apoptosis in the absence of Bax and Bak. Genes Dev 2001; 15:1481-6.

10 Lindsten T, Ross AJ, King A, et al. The combined functions of pro-apoptotic Bcl-2 family members Bak and Bax are essential for normal development of multiple tissues. Mol Cell 2000; 6:1389-99.

11 Rathmell JC, Lindsten T, Zong WX, et al. Deficiency in Bak and Bax perturbs thymic selection and lymphoid homeostasis. Nat Immunol 2002; 3:932-939.

12 Ranger AM, Malynn BA, Korsmeyer SJ. Mouse models of cell death. Nat Gen 2001; 28:113-8.

13 Veis DJ, Sorenson CM, Shutter JR, Korsmeyer SJ. Bcl-2-deficient mice demonstrate fulminant lymphoid apoptosis, polycystic kidneys, and hypopigmented hair. Cell 1993; 75:229-40.

14 Nakayama K, Nakayama K-I, Negishi I, et al. Targeted disruption of $b c l-2 \mathrm{ab}$ in mice: occurrence of gray hair, polycystic kidney disease, and lymphocytopenia. Proc Natl Acad Sci U S A 1994; 91:3700-4.

15 Kamada S, Shimono A, Shinto Y, et al. bcl-2 deficiency in mice leads to pleiotropic abnormalities: accelerated lymphoid cell death in thymus andspleen, polycystic kidney, hair hypopigmentation, and distorted small intestine. Cancer Res 1995; 55:354-9.

16 Print CG, Loveland KL, Gibson L, et al. Apoptosis regulator $\mathrm{Bcl}-\mathrm{w}$ is essential for spermatogenesis but appears otherwise redundant. Proc Natl Acad Sci U S A 1998; 95:12424-31.

17 Ross AJ, Waymire KG, Moss JE et al. Testicular degeneration in Bcl-w-deficient mice. Nat Gen 1998; 18:251-6.

18 Hamasaki A, Sendo F, Nakayama K, et al. Accelerated neutrophil apoptosis in mice lacking A1-a, a subtype of the bcl-2-related A1 gene. J Exp Med 1998; 188:1985-92.

19 Rinkenberger JL, Horning S, Klocke B, et al. Mcl-1 deficiency results in peri-implantation embryonic lethality. Genes Dev 2000;
14:23-7.

20 Motoyama N, Wang FP, Roth KA, et al. Massive cell death of immature hematopoietic cells and neurons in Bcl-x deficient mice. Science 1995; 267:1506-10.

21 Opferman J, Iwasaki H, Ong CC, et al. Obligate role of antiapoptotic Mcl-1 in the survival of hematopoietic stem cells. Science. 2005; 307:1101-4.

22 Opferman JT, Letai A, Beard C et al. Development and maintenance of $\mathrm{B}$ and $\mathrm{T}$ lymphocytes requires antiapoptotic Mcl-1. Nature 2003; 426:671-676.

23 Wagner KU, Claudio E, Rucker EB 3rd, et al. Conditional deletion of the Bcl-x gene from erythroid cells results in hemolytic anemia and profound splenomegaly. Development 2000; 127:4949-58.

24 Motoyama N, Kimura T, Takahashi T, et al. bcl-x prevents apoptotic cell death of both primitive and definitive erythrocytes at the end of maturation. J Exp Med 1999; 189:1691-8.

25 Hinds MG, Day CL. Regulation of apoptosis: uncovering the binding determinants. Curr Opin Struct Biol 2005; 15:690-9.

26 Petros AM, Medek A, Nettesheim DG, et al. Solution structure of the anti-apoptotic protein Bcl-2. Proc Natl Acad Sci U S A 2001; 98:3012-7.

27 Muchmore SW, Sattler M, Liang H, et al. X-ray and NMR structure of human $\mathrm{Bcl}-\mathrm{x}_{\mathrm{L}}$, an inhibitor of programmed cell death. Nature 1996; 381:335-41.

28 Liu X, Dai S, Zhu Y, et al. The structure of a Bcl- $\mathrm{x}_{\mathrm{L}} / \mathrm{Bim}$ fragment complex: Implications for Bim function. Immunity 2003; 19:341-52.

29 Hinds MG, Lackmann M, Skea GL, et al. The structure of Bcl-w reveals a role for the $\mathrm{C}$-terminal residues in modulating biological activity. EMBO J 2003; 22:1497-507.

30 Denisov AY, Madiraju MS, Chen G, et al. Solution structure of human Bcl-w: modulation of ligand binding by the C-terminal helix. J Biol Chem 2003; 278:21124-8.

31 Day CL, Chen L, Richardson SJ, et al. Solution Structure of Prosurvival Mcl-1 and Characterization of Its Binding by Proapoptotic BH3-only Ligands. J Biol Chem 2005; 280:4738-44.

32 Sattler M, Liang H, Nettesheim D, et al. Structure of Bcl- $\mathrm{x}_{\mathrm{L}}-\mathrm{Bak}$ peptide complex: recognition between regulators of apoptosis. Science 1997; 275:983-6.

33 Petros AM, Nettseheim DG, Wang Y, et al. Rationale for Bcl- $\mathrm{x}_{\mathrm{L}}$ / Bad peptide complex formation from structure, mutagenesis, and biophysical studies. Protein Sci 2000; 9:2528-34.

34 Huang DCS, Strasser A. BH3-only proteins - essential initiators of apoptotic cell death. Cell 2000; 103:839-42.

35 Bouillet P, Purton JF, Godfrey DI, et al. BH3-only Bcl-2 family member Bim is required for apoptosis of autoreactive thymocytes. Nature 2002; 415:922-6.

36 Enders A, Bouillet P, Puthalakath H, et al. Loss of the pro-apoptotic BH3-only Bcl-2 family member Bim inhibits BCR stimulation-induced apoptosis and deletion of autoreative B cells. J Exp Med 2003; 198:1119-26.

37 Hildeman DA, Zhu Y, Mitchell TC, et al. Activated T cell death in vivo mediated by pro-apoptotic Bcl-2 family member, Bim. Immunity 2002; 16:759-67.

38 Pellegrini M, Belz G, Bouillet P, Strasser A. Shut down of an acute $\mathrm{T}$ cell immune response to viral infection is mediated by the pro-apoptotic Bcl-2 homology 3-only protein Bim. Proc Natl Acad Sci U S A 2003; 100:14175-80.

39 Bouillet P, Metcalf D, Huang DCS, et al. Pro-apoptotic Bcl-2 
relative Bim required for certain apoptotic responses, leukocyte homeostasis, and to preclude autoimmunity. Science 1999; 286:1735-8.

40 Nakano K, Vousden KH. Puma, a novel pro-apoptotic gene, is induced by p53. Mol Cell 2001; 7:683-94.

41 Yu J, Zhang L, Hwang PM, et al. Puma induces the rapid apoptosis of colorectal cancer cells. Mol Cell 2001; 7:673-82.

42 Oda E, Ohki R, Murasawa H, et al. Noxa, a BH3-only member of the Bcl-2 family and candidate mediator of p53-induced apoptosis. Science 2000; 288:1053-8.

43 Villunger A, Michalak EM, Coultas L, et al. p53- and drug-induced apoptotic responses mediated by $\mathrm{BH} 3$-only proteins Puma and Noxa. Science 2003; 302:1036-8.

44 Jeffers JR, Parganas E, Lee Y, et al. Puma is an essential mediator of p53-dependent and -independent apoptotic pathways. Cancer Cell 2003; 4:321-8.

45 Shibue T, Takeda K, Oda E, et al. Integral role of Noxa in p53mediated apoptotic response. Genes Dev 2003; 17:2233-8.

46 Ranger AM, Zha J, Harada H, et al. Bad-deficient mice develop diffuse large B cell lymphoma. Proc Natl Acad Sci U S A 2003; 100:9324-9.

47 Yin X-M, Wang K, Gross A, et al. Bid-deficient mice are resistant to Fas-induced hepatocellular apoptosis. Nature 1999; 400:88691.

48 Puthalakath H, Villunger A, O'Reilly LA, et al. Bmf: a proapoptotic BH3-only protein regulated by interaction with the myosin $\mathrm{V}$ actin motor complex, activated by anoikis. Science 2001; 293:1829-32.

49 Suzuki M, Youle RJ, Tjandra N. Structure of Bax: coregulation of dimer formation and intracellular localization. Cell 2000; 103:645-54.

50 Wei MC, Zong WX, Cheng EH et al. Pro-apoptotic Bax and Bak: a requisite gateway to mitochondrial dysfunction and death. Science 2001; 292:727-30.

51 Lum JJ, Bauer DE, Kong M, et al. Growth factor regulation of autophagy and cell survival in the absence of apoptosis. Cell 2005; 120:237-48.

52 Hsu YT, Youle RJ. Bax in murine thymus is a soluble monomeric protein that displays differential detergent-induced conformations. J Biol Chem 1998; 273:10777-83.

53 Antonsson B, Montessuit S, Sanchez B, Martinou JC. Bax is present as a high molecular weight oligomer/complex in the mitochondrial membrane of apoptotic cells. J Biol Chem 2001; 276:11615-23.

54 Wolter KG, Hsu YT, Smith CL, et al. Movement of Bax from the cytosol to mitochondria during apoptosis. J Cell Biol 1997; 139:1281-92.

55 Nguyen M, Millar DG, Wee-Yong V, et al. Targeting of Bcl-2 to the mitochondrial outer membrane by a COOH-terminal signal anchor sequence. J Biol Chem 1993; 268:25265-8.

56 Lithgow T, van Driel R, Bertram JF, Strasser A. The protein product of the oncogene bcl-2 is a component of the nuclear envelope, the endoplasmic reticulum and the outer mitochondrial membrane. Cell Growth Differ 1994; 5:411-7.

57 Yang T, Kozopas KM, Craig RW. The intracellular distribution and pattern of expression of Mcl-1 overlap with, but are not identical to, those of Bcl-2. J Cell Biol 1995; 128:1173-84.

58 Kaufmann T, Schlipf S, Sanz J, et al. Characterization of the signal that directs $\mathrm{Bcl}-\mathrm{x}_{\mathrm{L}}$, but not Bcl-2, to the mitochondrial outer membrane. J Cell Biol 2003; 160:53-64.
59 Hsu YT, Wolter KG, Youle RJ. Cytosol-to-membrane redistribution of Bax and Bcl- $\mathrm{x}_{\mathrm{L}}$ during apoptosis. Proc Natl Acad Sci U S A 1997; 94:3668-72.

60 Mikhailov V, Mikhailova M, Pulkrabek DJ, et al. Bcl-2 prevents Bax oligomerization in the mitochondrial outer membrane. J Biol Chem 2001; 276:18361-74.

61 Nechushtan A, Smith CL, Lamensdorf I, et al. Bax and Bak coalesce into novel mitochondria-associated clusters during apoptosis. J Cell Biol 2001; 153:1265-76.

62 Griffiths GJ, Dubrez L, Morgan CP, et al. Cell damage-induced conformational changes of the pro-apoptotic protein Bak in vivo precede the onset of apoptosis. J Cell Biol 1999; 144:903-14.

63 Wei MC, Lindsten T, Mootha VK, et al. tBID, a membrane-targeted death ligand, oligomerizes BAK to release cytochrome $\mathrm{c}$. Genes Dev 2000; 14:2060-71.

64 Mikhailov V, Mikhailova M, Degenhardt K, et al. Association of Bax and Bak homo-oligomers in mitochondria. Bax requirement for Bak reorganization and cytochrome $c$ release. J Biol Chem 2003; 278:5367-76.

65 Shimizu S, Narita M, Tsujimoto Y. Bcl-2 family proteins regulate the release of apoptogenic cytochrome $c$ by the mitochondrial channel VDAC. Nature 1999; 399:483-7.

66 Cheng EH, Sheiko TV, Fisher JK, et al. VDAC2 inhibits BAK activation and mitochondrial apoptosis. Science 2003; 301:513-7.

67 Roucou X, Montessuit S, Antonsson B, Martinou JC. Bax oligomerization in mitochondrial membranes requires tBid (caspase8-cleaved Bid) and a mitochondrial protein. Biochem J 2002; 368:915-21.

68 Tan KO, Fu NY, Sukumaran SK, et al. MAP-1 is a mitochondrial effector of Bax. Proc Natl Acad Sci U S A 2005; 102:14623-8.

69 Green DR, Kroemer G. The pathophysiology of mitochondrial cell death. Science 2004; 305:626-9.

70 Kroemer G, Reed JC. Mitochondrial control of cell death. Nat Med 2000; 6:513-9.

71 Kluck RM, Esposti MD, Perkins G, et al. The pro-apoptotic proteins, Bid and Bax, cause a limited permeabilization of the mitochondrial outer membrane that is enhanced by cytosol. J Cell Biol 1999; 147:809-22.

72 Nakagawa T, Shimizu S, Watanabe T, et al. cyclophilin D-dependent mitochondrial permeability transition regulates some necrotic but not apoptotic cell death. Nature 2005; 434:652-8.

73 Baines CP, Kaiser RA, Purcell NH, et al. Loss of cyclophilin D reveals a critical role for mitochondrial permeability transition in cell death. Nature 2005; 434:658-62.

74 Basso E, Fante L, Fowlkes J, et al. Properties of the permeability transition pore in mitochondria devoid of cyclophilin D. J Biol Chem 2005; 280:18558-61.

75 Antonsson B, Montessuit S, Lauper S, et al. Bax oligomerization is required for channel-forming activity in liposomes and to trigger cytochrome $c$ release from mitochondria. Biochem $\mathrm{J}$ 2000; 345 Pt 2:271-8.

76 Saito M, Korsmeyer SJ, Schlesinger PH. Bax-dependent transport of cytochrome $c$ reconstituted in pure liposomes. Nat Cell Biol 2000; 2:553-5.

77 Kuwana T, Mackey MR, Perkins G, et al. Bid, Bax, and lipids cooperate to form supramolecular openings in the outer mitochondrial membrane. Cell 2002; 111:331-42.

78 Pavlov EV, Priault M, Pietkiewicz D, et al. A novel, high conduc- 
tance channel of mitochondria linked to apoptosis in mammalian cells and Bax expression in yeast. J Cell Biol 2001; 155:725-32.

79 Dejean LM, Martinez-Caballero S, Guo L, et al. Oligomeric Bax is a component of the putative cytochrome $c$ release channel $\mathrm{MAC}$, mitochondrial apoptosis-induced channel. Mol Biol Cell 2005; 16:2424-32.

80 Zong WX, Li C, Hatzuvassiliou G, et al. Bax and Bak can localize to the endoplasmic reticulum to initiate apoptosis. J Cell Biol 2003; 162:59-69.

81 Chen L, Willis SN, Wei A, et al. Differential targeting of prosurvival Bcl-2 proteins by their BH3-only ligands allows complementary apoptotic function. Mol Cell 2005; 17:393-403.

82 Kuwana T, Bouchier-Hayes L, Chipuk JE, et al. BH3 Domains of BH3-Only Proteins Differentially Regulate Bax-Mediated Mitochondrial Membrane Permeabilization Both Directly and Indirectly. Mol Cell 2005; 17:525-35.

83 Letai A, Bassik M, Walensky L, et al. Distinct BH3 domains either sensitize or activate mitochondrial apoptosis, serving as prototype cancer therapeutics. Cancer Cell 2002; 2:183-92.

84 Cartron PF, Gallenne T, Bougras G, et al. The first alpha helix of Bax plays a necessary role in its ligand-induced activation by the BH3-only proteins Bid and Puma. Mol Cell 2004; 16:807-18.

85 Marani M, Tenev T, Hancock D, et al. Identification of novel isoforms of the $\mathrm{BH} 3$ domain protein Bim which directly activate Bax to trigger apoptosis. Mol Cell Biol 2002; 22:3577-89.

86 Wang K, Yin X-M, Chao DT et al. BID: a novel BH3 domainonly death agonist. Genes Dev 1996; 10:2859-69.

87 Zhu Y, Swanson BJ, Wang M, et al. Constitutive association of the proapoptotic protein Bim with Bcl-2-related proteins on mitochondria in T cells. Proc Natl Acad Sci U S A 2004; 101:7681-6.

88 Korsmeyer SJ, Wei MC, Saito M, et al. Pro-apoptotic cascade activates Bid, which oligomerizes Bak or Bax into pores that result in the release of cytochrome c. Cell Death Differ 2000; 7:1166-73.

89 Jeong SY, Gaume B, Lee YJ, et al. Bcl-x(L) sequesters its Cterminal membrane anchor in soluble, cytosolic homodimers. Embo J 2004; 23:2146-55.

90 Oltvai ZN, Milliman CL, Korsmeyer SJ. Bcl-2 heterodimerizes in vivo with a conserved homolog, Bax, that accelerates programmed cell death. Cell 1993; 74:609-19.

91 Krajewski S, Tanaka S, Takayama S, et al. Investigation of the subcellular distribution of the bcl-2 oncoprotein: residence in the nuclear envelope, endoplasmic reticulum, and outer mitochondrial membranes. Cancer Res 1993; 53:4701-14.

92 Wang K, Gross A, Waksman G, Korsmeyer SJ. Mutagenesis of the BH3 domain of Bax identifies residues critical for dimerization and killing. Mol Cell Biol 1998; 18:6083-9.

93 Willis SN, Chen L, Dewson G, et al. Pro-apoptotic Bak is sequestered by $\mathrm{Mc1}$ and $\mathrm{Bcl}-\mathrm{x}_{\mathrm{L}}$, but not $\mathrm{Bcl}-2$, until displaced by BH3-only proteins. Genes Dev 2005; 19:1294-305.

94 Cuconati A, Mukherjee C, Perez D, White E. DNA damage response and Mcl-1 destruction initiate apoptosis in adenovirusinfected cells. Genes Dev 2003; 17:2922-32.

95 Nijhawan D, Fang M, Traer E, et al. Elimination of Mcl-1 is required for the initiation of apoptosis following ultraviolet irradiation. Genes Dev 2003; 17:1475-86.

96 Mei Y, Du W, Yang Y, Wu M. Puma(*)Mcl-1 interaction is not sufficient to prevent rapid degradation of Mcl-1. Oncogene 2005;
24:7224-37.

97 Zhong Q, Gao W, Du F, Wang X. Mule/ARF-BP1, a BH3-Only E3 Ubiquitin Ligase, Catalyzes the Polyubiquitination of Mcl-1 and Regulates Apoptosis. Cell 2005; 121:1085-95.

98 Holcik M, Sonenberg N. Translational control in stress and apoptosis. Nat Rev Mol Cell Biol 2005; 6:318-27.

99 Le Gouill S, Podar K, Amiot M, et al. VEGF induces Mcl-1 upregulation and protects multiple myeloma cells against apoptosis. Blood 2004; 104:2886-92.

100 Wang JM, Lai MZ, Yang-Yen HF. Interleukin-3 stimulation of $\mathrm{mcl}-1$ gene transcription involves activation of the PU.1 transcription factor through a p38 mitogen-activated protein kinase-dependent pathway. Mol Cell Biol 2003; 23:1896-909.

101 Huang HM, Huang CJ, Yen JJ. Mcl-1 is a common target of stem cell factor and interleukin-5 for apoptosis prevention activity via MEK/MAPK and PI-3K/Akt pathways. Blood 2000; 96:176471.

102 Domina AM, Vrana JA, Gregory MA, et al. Mcl-1 is phosphorylated in the PEST region and stabilized upon ERK activation in viable cells, and at additional sites with cytotoxic okadaic acid or taxol. Oncogene 2004; 23:5301-15.

103 Inoshita S, Takeda K, Hatai T, et al. Phosphorylation and inactivation of myeloid cell leukemia 1 by JNK in response to oxidative stress. J Biol Chem 2002; 277:43730-4.

104 Johnstone RW, Ruefli AA, Lowe SW. Apoptosis: a link between cancer genetics and chemotherapy. Cell 2002; 108:153-64.

105 Vogelstein B, Lane D, Levine AJ. Surfing the p53 network. Nature 2000; 408:307-10.

106Schimmer AD, Hedley DW, Chow S, et al. The BH3 domain of Bad fused to the Antennapedia peptide induces apoptosis via its alpha helical structure and independent of Bcl-2. Cell Death Differ 2001; 8:725-33.

107 Vieira HL, Boya P, Cohen I, et al. Cell permeable BH3-peptides overcome the cytoprotective effect of Bcl-2 and Bcl- $\mathrm{X}_{\mathrm{L}}$. Oncogene 2002; 21:1963-77.

108 Wang JL, Zhang ZJ, Choksi S, et al. Cell permeable Bcl-2 binding peptides: a chemical approach to apoptosis induction in tumor cells. Cancer Res 2000; 60:1498-502.

109 Walensky LD, Kung AL, Escher I, et al. Activation of Apoptosis in vivo by a Hydrocarbon-Stapled BH3 Helix. Science 2004; 305:1466-70.

110 Wang JL, Liu D, Zhang ZJ, et al. Structure-based discovery of an organic compound that binds $\mathrm{Bcl}-2$ protein and induces apoptosis of tumor cells. Proc Natl Acad Sci U S A 2000; 97:7124-9.

111 Degterev A, Lugovskoy A, Cardone M, et al. Identification of small-molecule inhibitors of interaction between the $\mathrm{BH} 3$ domain and Bcl- $\mathrm{x}_{\mathrm{L}}$. Nat Cell Biol 2001; 3:173-82.

112 Baell JB, Huang DCS. Prospects for targeting the Bcl-2 family of proteins to develop novel cytotoxic drugs. Biochem Pharmacol 2002; 64:851-63.

113 Rutledge SE, Chin JW, Schepartz A. A view to a kill: ligands for Bcl-2 family proteins. Curr Opin Chem Biol 2002; 6:479-85.

114 Oltersdorf T, Elmore SW, Shoemaker AR, et al. An inhibitor of $\mathrm{Bcl}-2$ family proteins induces regression of solid tumours. Nature 2005; 435:677-81.

115 MacCallum DE, Melville J, Frame S, et al. Seliciclib (CYC202, R-Roscovitine) induces cell death in multiple myeloma cells by inhibition of RNA polymerase II-dependent transcription and down-regulation of Mcl-1. Cancer Res 2005; 65:5399-407. 
116 Raje N, Kumar S, Hideshima T, et al. Seliciclib (CYC202 or R-roscovitine), a small-molecule cyclin-dependent kinase inhibi- tor, mediates activity via down-regulation of Mcl-1 in multiple myeloma. Blood 2005; 106:1042-7. 